\title{
Changing Creative Writing in America
}

\author{
Mitchell R. James
}

Lakeland Community College

mjames24@1akelandcc.edu

\section{Review of}

Harper, Graeme, ed. Changing Creative Writing in America: Strengths, Weaknesses, Possibilities. Multilingual Matters, 2017.

Imagine a group of creative writers and teachers of creative writing sitting around a giant conference table. Projected on a wall is the title of this book. Imagine these individuals coming together because they plan to discuss changing creative writing in America, almost as if they want to discuss the pros and cons of doing so for the first time. At first, this is how the title of this collection read for me-a book about the strengths, weaknesses, and possibilities of implementing new thoughts and ideas into the already-established paradigms of creative writing. To a large degree, this collection does just that; it fosters much discussion (and disagreement) about where creative writing is currently and where it should be heading. However, one thing is certain, change in creative writing is already here. It has been here. This book could have been just as aptly titled Creative Writing in America: Strengths, Weaknesses, and Possibilities, as this collection is just as much about the strengths, weakness, and possibilities of creative writing in the current moment as it is about the direction of creative writing's future.

Graeme Harper opens the collection by discussing creative writing as a tripartite structure, one which includes both writers' internal selves and their environments. In this discussion, Harper adapts three words from their everyday usage and applies them in innovative ways to the act of writing creatively. These words are aliveness, echolocation, and habitat. The relationship between these three writerly processes provides a large — somewhat abstract, somewhat not—framework for much of what's published in this collection. Harper defines aliveness as life "experiences" so deeply impactful to our psyche and so intricately interwoven with one another that they come back often and out of necessity (5). This aliveness drives the creative writer. One could align aliveness, as Harper details it, with the "vigor of mental conception" (Grube 10) — or genius - inherent in Longinus' definition of the sublime in writing, which makes aliveness quite abstract. 
However, one might also argue that an understanding of aliveness might be being defined more specifically in Dianne Donnelly's chapter "The Convergence of Creative Writing Processes and Their Neurological Mapping," which posits early that "Little is known about how the initiation and inception of creative ideas, insights, and intuition arise in the brain" (95). After this observation, Donnelly partakes in groundbreaking work exploring "the integration and convergence of creative processes" with neurobiology to better understand how creative cognition functions increase the creative process. In short, aliveness appears to be a recurring mental phenomenon driven by past experiences. One might argue Donnelly provides scientific-based evidence to support Harper's intriguing and more philosophical observations. This connection between Harper's introduction to the collection and the work of other contributors continues throughout the manuscript.

Another of Harper's terms, echolocation, is the recursive relationship between every element of a writer's process at the micro level and the world around him/her. Though every author in this collection discusses the relationship of creative writing at micro and macro levels, especially in regards to creative writing as a process and product, Katherine Haake does so on a spiritual level. Haake discusses creative writing as not only process or product but, instead, as a way of "being" (47). Part of that way of being is living a life of "sustainable literary practice" (39) and doing so for a long time (44), a practice I understand as a writer who writes daily. However, the other way of being, which Haake discusses as a residual effect of living a life of sustainable literary practice for years, is a writing state I'm familiar with but not so apt to discuss with students, one she calls the spiritual state. Haake's discussion adds unique complexities and possibilities to Harper's definition of echolocation. Haake maintains that part of what sustains her as a writer is the person (or non-person) she becomes when she writes (48). She ceases to be her individual self by becoming connected to all else (48). This moment, Haake entertains, is not about the "“thing"” or "symbol"” but is about the "space between" (48). In this instant, Haake believes she is making true art, an endeavor that can only occur "when inner and outer come together" (47). Writing as a way of being that is "always against death, obliteration, extinction, and non-writing" (46) is, inevitably, a way of being that is always engaged with a surrounding existence that, in turn, engages back - echolocation as Harper explains it.

Habitat, to discuss another of Harper's terms in relation to the work of other contributors in this collection, involves both micro (individual writers) and macro (their ecosystems) elements of writers' lives, which are constituted by both "found and fortuitous manifestations" (2). It is within this realm of habitat where several authors in this collection bare their work. As a case in point, Alexandria Peary, in her chapter "Histories and Historiography in Creative Writing Studies," argues that practitioners of creative writing have an understanding of their past that is "largely blank" (17). Peary calls for a surfeit of historiographic research, emboldening teachers and practitioners of creative writing to understand further the history of its pedagogies (21), the effects of "historical materials" on current manifestations and understandings of creative writing $(23,25)$, and to identify the influences of non-elite, non-academic sources on current understandings of teaching and producing creative texts (27). As a guideline 
on how to do so, Peary proffers a handful of historiographic texts from composition studies (25). Taking these steps, Peary believes, pays homage to the disciplinary predecessors who have afforded us the opportunity to have these very discussions, and in doing so, we bolster our own worth as writers and teachers of creative writing (22).

Still with Harper's notion of habitat in mind, Bruce Horner also argues for a stronger understanding of disciplinary situatedness in creative writing but with less plurality than Peary suggests. Though Horner makes a handful of arguments about creative writing, composition, and their relationship in his chapter, there are two points I find particularly compelling: that we should be weary of redefinition by addition (115) and that the power of creativity is not in its novelty but in its ordinary uses (124). Horner is warning, more or less, for creative writing to continue its work in-house instead of rebranding itself by latching on to other disciplines. This step, Horner argues, has happened already in composition studies and has proven deleterious, as it has diluted various aspects of writing composition (115). Putting Horner's theory to praxis, Stephanie Vanderslice, in her chapter, reviews a "representative list" (71) of handbooks on creative writing to find that, unlike handbooks in composition studies, those in creative writing forward more robust discussions on the theories behind their practice and teaching of creative writing. However, converse to Horner's position is that of Tim Mayers, who argues that creative writing needs to be redefined as an act "in service to writing [and not] writers" (52). Though not in conflict with Horner's position initially, Mayers argues this redefinition lies in the gray area between the dichotomous identity of writing as either a skills-based (composition) or mysterious (creative writing) enterprise. This binary, he purports, is supported and sometimes challenged in both creative writing and composition. To resolve this dichotomy, Mayers suggests, will take analysis in not only creative writing and composition but also in spaces outside the educational setting, where a "revised conception of writing" is needed (61). Add to this already dissentious discussion Kate Kastelnik's chapter, where she admits she "no longer teaches pure creative writing" (144-145); Patrick Bizzaro and Christine Bailey's chapter, arguing that the creative writing process, especially the act of writing poetry, applies to various fields and has been contributing to human knowledge long before its codification in higher education; and Joseph Rein's chapter, where he argues against departmental totalitarianism (the kind Horner appears to encourage) and, instead, for wide interdisciplinarity—and it becomes clear creative writing is certainly changing and is on unstable ground.

Changing Creative Writing in America presents the complexity inherent in the thought, teaching, and production of creative writing in the US, a complexity that this book, and others like it, demonstrates has always been there. However, the academic discourse surrounding these complexities are new, and as thoughts on the teaching and production of creative writing burgeon in various directions, so do the thoughts on what's "best" for the future of the field. This is the same embattled position other fields in English studies have gone (and are going) through. I'm alluding to Sir Arthur Quiller-Couch's need to validate the teaching of English literature in 1913 (Dawson 6) and the various battles composition studies has fought and continues to fight to establish its identity and role as a field. The corresponding 
and conflicting perspectives in this collection are a sign of growth in the field of creative writing/ creative writing studies. It is when the practitioners and educators within a field are quiet about their history and practices that is disconcerting - a silence adhered to by creative writing for most of its short institutional life, but no more, thanks to collections like this one.

\section{Works Cited}

Dawson, Paul. Creative Writing and the New Humanities. Routledge, 2005.

Longinus. On Great Writing. Translated by G.M.A. Grube, Hackett, 1991. 